\title{
Role of Communication Skills in Education.
}

\author{
Sudeshna Das
}

Let us first define the key words of this topic...

Communication: Communication is the interaction between two or more animate or inanimate things. Communication (from Latin "communis", meaning to share) is the activity of conveying information through the exchange of thoughts, messages, or information, as by speech, visuals, signals, writing, or behavior.(1)

Skills: Skills, in context of communication is the art of exchanging thoughts or ideas from mind to mind or soul to soul of individuals with equal reciprocation.

Education: Education generally means imparting information in a systematic and scheduled manner. Education in its general sense is a form of learning in which knowledge, skills, and habits of a group of people are transferred from one generation to the next through teaching, training, research, or simply through autodidacticism. Generally, it occurs through any experience that has a formative effect on the way one thinks, feels, or acts.(2)

Summing up these definitions, the role of communication skills in education in today's context is, teaching and training a child with the basic skills of communication, that is listening, speaking, reading and writing to establish himself successfully in the society and make an affluent livelihood.

One of the drawback of the above aim of education is this that it considers all human beings having same potential and ignores the individuality of an individual being. It considers human beings as a dead rock which can be carved as per the prevailing market demand. It fails to consider human beings as a living soul which grows and evolves as per his own potential. This attitude of guardians or teachers generates a conflict in the childs's mind. In my years of teaching experience, one thing generally observed is that many students are pursuing great professional courses not because they are interested, but because their parents think these courses will make them successful professionals. Once they realize that this profession might not be self fulfilling or not their cup of tea, they don't hesitate to leave the same and join some other. Many times it is at the cost of their livelihood, comfort and affluence. Hope the readers will agree to my view.

However, only looking forward towards earning livelihood may be a too shallow aim of education. To me the purpose of education is much wider as well as deeper, as explained in the following sentence "The chief aim of education should be to help the growing soul to draw out that in itself which is best and make it perfect for a noble use".(3)Here comes the role of communication skills of a teacher and guardian, how they can bring out the best in a child.

\section{Discussion And Reasons:}

Swami Vivekananda in one of his writings has mentioned that one cannot have mangoes on a neem tree. But certainly a good care taken by a gardener can grow an excellent neem tree. In Swamiji's words,

"Thus Vedanta says that within man is all knowledge even in a boy it is so, and it requires only an awakening and that much is the work of a teacher". To drive his point home, he refers to the growth of a plant. Just as in case of a plant, one cannot do anything more than supplying it with water, air and manure, while it grows from within its own nature, so is the case of human child. (4)

I strongly believe in this view, that what is within comes out and manifests externally. Keeping this view in mind one can say that the prime responsibility of a teacher is to identify, what is there hidden in a child. To bring out the hidden man in us or what is termed as Atmagyan. Here comes the role of the teacher as a communicator or a facilitator or a gardener, to bring out the hidden potential of the child and give it a right direction. Once the potential and area of interest has been identified in a child, the child gets the direction of learning and educating himself. By communicating to the students and understanding them, a teacher plays a dual role of understanding and gauging the real interest of the child and making him realize his direction . It's the duty of the teacher and guardian to communicate it to the individual, make him realize his potential and show the right of interest. This can be done only by communicating all the time, apart from a formal 
communication of regular contents of classroom teaching. As it has been observed that a child who has been very fond of sketching and colouring, may not turn out to be a good painter but a good architect. As his sketching have always been three dimentional and selection of colours have been very subtle. So there has been a two way communication between the child and teacher and guardians which really needed a skillful eye and indepth understanding to bring out the hidden potential. This is an important aspect of communication skills in education which is not stereotyped.

I have had the privilege of visiting two International schools, one in Kodaikanal, Tamil Nadu and the other in Pune, Maharashtra. What appealed me there was the student-teacher relationship. They addressed each other by their first name. The classrooms were wide and open. The number of students per class is very less, nearly twenty and the mode of teaching is by virtue of discussion. This school focused on many activities rather than classroom teaching and direct textbook dealing. It really aimed at the all round development of a child, nurturing their hidden talents. Though the school had a regular timing, but the association with teacher and student continued beyond the school hours. For example, I had an opportunity to attend one of the informal evening session in one of the teacher's residence. The topic of discussion was 'The Prophet' by Khalil Gibran. The best part was that it was arranged in the courtyard and each student made themselves comfortable on the laid chairs, mats, cushions, steps and even on the floor. Few also volunteered to prepare tea and serve it to all, while the teacher was busy discussing and asking everyone's opinion. Finally she summed up the session giving her opinion but not stressing on what it should be. This session actually enhanced a great deal on learning for life among the students as well as nurtured both their verbal and non verbal communication skills.

Apart from verbal communication in education, the non verbal communication plays a greater role in educating a student. The best part is that non verbal communication is $63-93 \%$ of the total communication. This major part of communication plays a vital role in educating a person for lifetime. The words of Swami Vivekananda appealed me a lot and evoked in me to learn more about understanding and communicating with a child, apart from the regular communication skills we incorporate while teaching in the classroom. Eventually I happened to read an article on Sri Aurobindo's thought on Integral Education. The thought of Integral Education goes as follows:

i) The first principle of true teaching is that nothing can be taught. The teacher is not an instructor or taskmaster, he is a helper and guide.(5)

Pondering upon the first principle of education by Sri Aurobindo, I feel it's not the superiority of age that makes us a teacher or gaurdian, but the experience which we have gained while growing up, that we can share and communicate with the child. This will certainly have a lasting impact in his memory than the formal lessons taught in the classrooms. The child should be graded and applauded for what he knows and not condemned for what he does not know and cannot actually figure out. One of the children in the class had great difficulty in learning addition and subtraction. It just bounced out of his head. That child had a great liking for flowers and would pluck one flower from his garden everyday to offer his teacher. The teacher took this context to explain him the concept of addition and subtraction and the child understood it well as he thought it was something he liked and realised that actually addition and subtraction was very simple, but the monotony of numbers on the blackboard was very boring. So, this thoughtful and innovative communication by the teacher helped to educate the child for lifetime.

ii) The second principle is that the mind has to be consulted in its own growth. The idea of hammering the child into the shape desired by the parent or teacher is a barbarous and ignorant superstition.(6)

If the mind must be consulted in its own growth, then our first task as teachers is to observe the child. What kind of a child is he? What is his temperament? What are his aspirations? What are his instinctive movements? Based on these observations we will select the best approach to interact with him. There are three broad types of temperament. There are the types who understand by explanation, whose minds are more intellectually oriented, and to them you explain, "See, this is harmful because it leads to such and such results," and they immediately understand and change. You don't need to say anything more. There is another type whose temperament is more emotionally oriented. You have to move his emotions or tap his sense of self-respect. To this child you will reach out emotionally, "How do you feel after doing this? This behavior is not worthy of you." No explanation needed; the child has got the message in his language. There is a third kind of temperament which is more materially oriented, living in the sensory experience. To these children you have to show the consequences of their actions, "If you do this then these are the consequences that you will have to face. If you keep disturbing your neighbour, then you will have to sit on a chair that has no neighbour." This makes sense to him. And sometimes it actually helps to have him sit there to experience sensorily what it is like. We realise now how important it is to communicate in terms of the child's understanding and temperament. We may express ourselves most wonderfully with emotions, but if the receiving part is the mind which wants to understand, then very little will have been communicated and much would have been misunderstood. By knowing the temperament of the child and communicating accordingly, your message is received with clarity and with immediate impact.(7) 
iii) The third principle of education is to work from the near to the far, from that which is to that which shall be.(8)

To make a child understand a subject matter, always examples should be quoted from his surrounding environment which he can easily correlate and understand and slowly pave the path to understand and visualise difficult matter. It has been observed that children often think in their mother tongue, and translate it in English or Hindi to finally put forth their views. In this course, there might be grammatical and syntax error, but the expression is always clear. This behaviour goes on till adulthood. Such communication promotes better understanding and learning.

Strategies for implimentations:

Keeping the above into consideration and taking steps in educating a child, the communication skills play a vital role in shaping up his future. Apart from verbal and written communication, nonverbal communication is of equal or greater importance.

- Before imparting any knowledge, the teacher should first gain the confidence of the child. This can be done only by non verbal communication.

- The unspoken thread of communication develops love, faith and trust between the teacher and the taught and teaching-learning process becomes smooth and easy.

- Praise should be communicated both verbally and non verbally to strengthen the level of appreciation.

- Care should be taken that a child should never be ridiculed for the mistakes or follies done by the teacher or guardians.

- Right example should be put forth a child which the adults want the children to follow, as most children hero worship their elders and unknowingly follow their traits.

- To bring out the hidden potential of a child, he should be subjected to a lot of creative work as well as creative writing.

- Physical and extra curricular activities (debate, dramatics, dance) should have same weightage as other subjects .

- This will surface his inner being and area of interests and eventually he can be directed to pursue his dreams.

- The child should be exposed to a variety of disciplines and allowed to make a choice by his own consent rather than directing him on a particular line.

- Communicating with a child to educate him in true self will need a lot of thoughtfulness and self indulgence on the part of guardians and teachers.

Whenever you find yourself with a difficulty and do not know how to proceed, refer to these three principles and you will find the solution. There is no theoretical or practical problem of education that is not resolved by the guidance of these three magic notions. Summing up , the role of communication skills in education is, bringing out the deep seated potential of a person to give it a concrete appearance. It is educating a person in such a way that he can communicate with the world skilfully pouring out his heart and soul in all his activities.

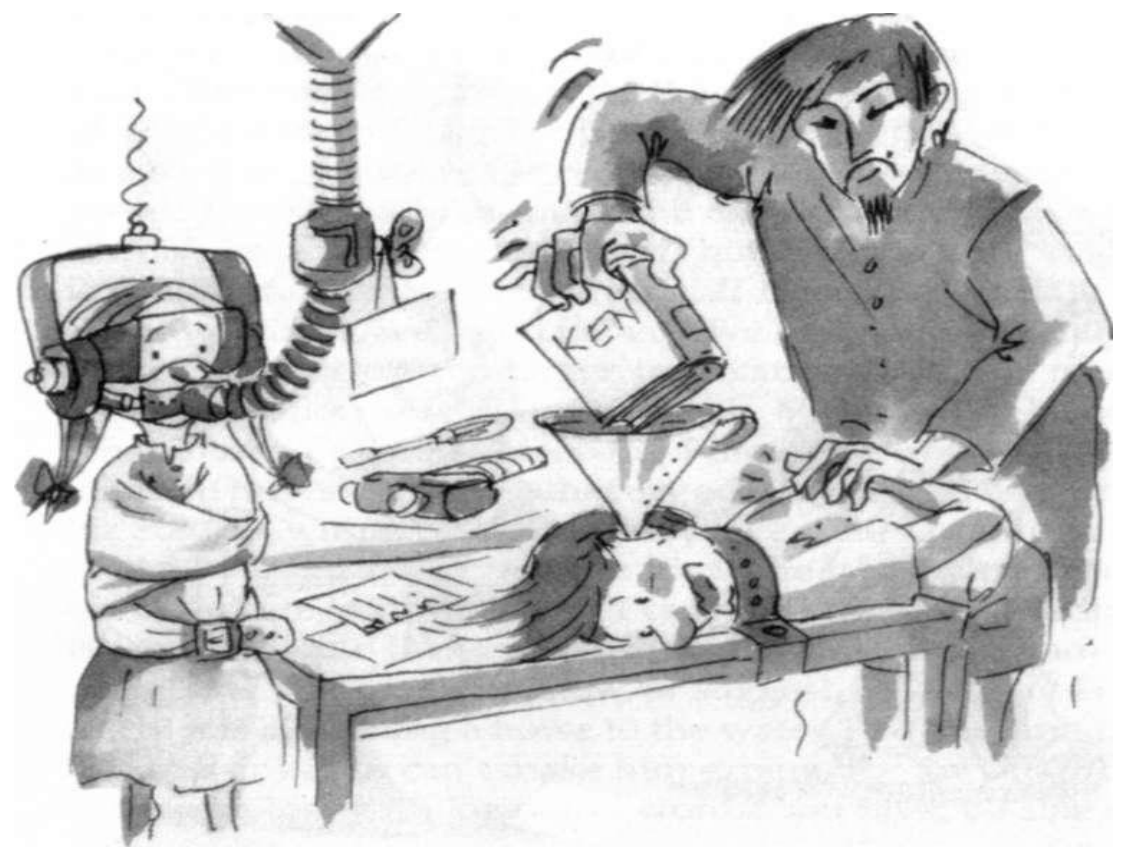




\section{References:}

[1]. Wikipedia: Communication.

[2]. Wikipedia: Education.

[3]. Sri Aurobindo, Early Cultural Writings, selections, (CWSA 1) pp. 383-392. A System of National Education Some Preliminary Ideas.

[4]. (By Dr. Sudipa Dutta Roy, Education In the Vision of Swami Vivekananda, www,esamskrita.com)

[5]. Sri Aurobindo, Early Cultural Writings, selections, (CWSA 1) pp. 383-392. A System of National Education Some Preliminary Ideas

[6]. Sri Aurobindo, Early Cultural Writings, selections, (CWSA 1) pp. 383-392. A System of National Education Some Preliminary Ideas.

[7]. Introduction to Integral Education an Inspirational Guide, Shraddhalu Ranade.

[8]. Sri Aurobindo, Early Cultural Writings, selections, (CWSA 1) pp. 383-392. A System of National Education Some Preliminary Ideas. 